\title{
Epistemic Infinitism and the Conditional Character of Inferential Justification
}

\begin{abstract}
In this paper, I will present and defend an argument from the conditional character of inferential justification (the argument from conditionality) against the version of epistemic infinitism Klein advances. More specifically, after proposing a distinction between propositional and doxastic infinitism, which is based on a standard distinction between propositional and doxastic justification, I will describe in considerable detail the argument from conditionality, which is mainly an argument against propositional infinitism, and clarify some of its main underlying assumptions. There are various responses to be found in Klein's works to this argument, and my aim is to show that none of those responses can be plausibly held without infinitism losing its title to being a genuine non-skeptical alternative.
\end{abstract}

Keywords: Epistemic infinitism, epistemic justification, propositional justification, doxastic justification, Peter Klein.

If one belief is based on some reasons, but those reasons do not have a basis themselves, then it looks as if what depends on those reasons is no better justified than a belief for which one has no reasons at all.

Richard Feldman, Epistemology

\section{Introduction}

Epistemic infinitism (or simply "infinitism") is one of the logically possible answers to a question about the structure of epistemic justification: how must our justificatory reasons for the propositions that we believe be organized in order for us to be justified in believing those propositions? According to infinitism, the structure of justificatory reasons is infinite and nonrepeating: a proposition, $\mathrm{P}$, is justified for a person, $\mathrm{S}$, only if there is an infinite set of propositions available to $\mathrm{S}$ that can be arranged in a non-repeating series such that the first member, $\mathrm{R}_{1}$ is a reason for $\mathrm{P}$, and the second member, $\mathrm{R}_{2}$ is a reason for $\mathrm{R}_{1}$, and the third member, $\mathrm{R}_{3}$ is a reason for $\mathrm{R}_{2}$, and so on. ${ }^{1}$ Infinitism holds that the only type of series of reasons that can increase the rational credibility of a proposition is one that has no repeating members and has no last member.

\footnotetext{
${ }^{1}$ This is the infinitist account of propositional justification. The distinction between propositional and doxastic justification and the infinitist thesis about the latter will be presented and discussed below.
} 
The common philosophical attitude that characterizes the history of infinitism is either neglect or quick dismissal. Infinitism is generally regarded as so obviously false that it is rejected out of hand without any careful examination: its cavalier rejection, if any given at all, is in general purported to pave the way for a sustained discussion of what is received as the only two genuine rival views about the structure of epistemic justification, namely, foundationalism and coherentism. As is well known, however, the long history of being treated as a mere foil has been interrupted by a series of admirable works since the late 1990s by Peter Klein, who has not only managed to show that infinitism is able to avoid some of the most common arguments against it but also articulated some of the subtle differences between a family of views that might go under that generic title. It is fair to say that Klein has succeeded, almost single-handedly, in promoting infinitism from a dialectical bogeyman to a worthy competitor. ${ }^{2}$

This paper is hereafter divided into three sections. In section 2, I will briefly present the distinction between propositional and doxastic justification and Klein's conception of the latter. This will enable us to give an initial formulation of epistemic infinitism about propositional justification (which I will call propositional infinitism) and about doxastic justification (which I will call doxastic infinitism). In section 3, I will propose an argument against propositional infinitism, the argument from conditionality, and try to make explicit some of its underlying assumptions. In section 4, I will present Klein's responses to the argument and argue that a dilemma arises for Klein's defense of infinitism, neither horn of which helps the infinitist cause of formulating a non-skeptical alternative to foundationalism and coherentism.

\footnotetext{
${ }^{2}$ Here is a representative but incomplete list of Klein's works that defend epistemic infinitism: (1998, 1999, 2000, 2005a, 2007a, 2011, 2014). The version of infinitism Klein upholds has gone through a series of transformations throughout these years, but there is a consistent and recurring idea that Klein defends, which I will clarify and argue against below. Klein's works have inspired a large and still growing literature on infinitism. Here is again a representative but incomplete sample: Fantl (2003), Cling (2004), Aikin (2005, 2008, 2011), Wright (2013), Peijnenburg and Atkinson (2013), Turri (2009a, 2009b, 2010a). Ad Infinitum (2014), a collection, edited by Turri and Klein, of fourteen papers at the cutting edge of research on epistemic infinitism, deserves special emphasis.
} 


\section{Epistemic Infinitism about Propositional and Doxastic Justification}

An important distinction any account of epistemic justification must respect is surely between propositional and doxastic justification, which is, to my knowledge, first clearly introduced by Firth (1978). After noting that "the term 'warranted belief' is ambiguous" (p. 217), Firth presents the distinction between propositional and doxastic warrant (or justification) by the following well-known Holmes-Watson example:

Let us suppose, for example, that Holmes knows at a certain time $t$ that the coachman committed the murder. Holmes has studied the mud on the wheels of the carriage and from this and other evidence has reached a correct conclusion by rational inference. We may then employ the term 'warranted' to say two quite different things. We may say that the proposition 'The coachman did it' is warranted for Holmes at $t$. It is warranted for Holmes and not for Watson because it is warranted on the basis of evidence possessed only by Holmes. But we may also say that Holmes, because his conclusion is based rationally on the evidence, is warranted in believing that the coachman did it. (p. 218)

According to Firth, then, a proposition, $\mathrm{P}$, is propositionally justified for a subject, $\mathrm{S}$, just in case there is an epistemically adequate basis (support or "evidence") for P that is available to $\mathrm{S}^{3}$; and, a belief that $\mathrm{P}$ is doxastically justified for $\mathrm{S}$ just in case $\mathrm{S}$ 's belief that $\mathrm{P}$ is formed, roughly, in an epistemically responsible manner (or "is based rationally on the evidence"). The distinction between propositional and doxastic justification rests on the traditional distinction between the (possible) contents of believing (i.e. propositions) and the attitude of believing: when we are asking whether a proposition is justified for a subject, we are asking a question about what Firth calls "a 'logical' relationship" (p. 219) between that proposition and certain psychological states of the subject - namely, whether the latter provide some sort of objective support for the former ${ }^{4}$; however, when we are asking whether a belief that $\mathrm{P}$ is doxastically justified for $\mathrm{S}$, we are asking a question about the way $\mathrm{S}$ forms the attitude of believing towards

\footnotetext{
${ }^{3}$ In this paper, I will take the notion of evidential support (and epistemic basis) for granted. For an account of this notion, see, for instance, Conee and Feldman (2008).

${ }^{4}$ Kvanvig and Menzel (1990) characterizes a traditional approach to justification as one that "holds that what is fundamental to justification is some abstract relation between propositions which we can call the evidence relation. Justification obtains for a person's belief, according to such theories, when these abstract relations are instanced in some specified type of psychological reality" (p. 236). Firth's conception of the distinction between propositional and doxastic justification embraces this traditional approach.
} 
$\mathrm{P}$ - namely, whether the manner at which $\mathrm{S}$ "reaches" the belief that $\mathrm{P}$ is epistemically responsible. $^{5}$

Firth's distinction between propositional and doxastic justification entails that a proposition might be justified for a subject even if the subject is not doxastically justified in believing that proposition. Doxastic justification requires not only believing but also epistemically responsible believing, and propositional justification requires neither. So, from the fact that $\mathrm{P}$, which $\mathrm{S}$ believes, is justified for $\mathrm{S}$, we cannot conclude that $\mathrm{S}$ is doxastically justified in believing P since S might believe, as Firth notes, "for the wrong reasons or even as a consequence of hypnotic suggestion" (p. 220). However, from the fact that $S$ is doxastically justified in believing $\mathrm{P}$, we can conclude that $\mathrm{P}$ is justified for $\mathrm{S}$. Firth writes:

$S$ cannot be warranted in believing $p$ unless $S$ arrives at his belief in a way that corresponds, in an appropriate way, to the evidential relationships in virtue of which $p$ is warranted for $S$. (p. 220)

Note that Firth here claims not only that doxastic justification requires propositional justification but also, as the talk of appropriate correspondence suggests, that there is what one might call a "structural similarity" constraint on doxastic justification, a constraint that originates from the way in which propositional justification is structured. ${ }^{6}$ The way in which $\mathrm{S}$

\footnotetext{
${ }^{5}$ The definitive characteristic of Firth's notion of doxastic justification is that it requires believing a proposition on the basis of an epistemically adequate basis (roughly, good reasons). However, Firth also appears to assume that a subject can only believe a proposition on the basis of good reasons if she "reaches" or "arrives at" that belief through being engaged in the activity of justifying it (offering those good reasons for it in conversation or sotto voce). This assumption might appear unnecessarily restrictive: one might believe a proposition on the basis of good reasons even if one's coming to hold that belief is not caused by an activity of offering reasons in its favor. The cause of a belief state need not be an overt mental activity of offering reasons for having it in order for that state to be based on good reasons: the subject's basing a belief on good reasons is one thing, and that belief's being based on good reasons is another thing. (One of Goldman's examples is helpful here: "My belief that there is a fire in the neighborhood is based on... my belief that I hear a fire engine. But I have not gone through a process of explicit reasoning, saying "There's a fire engine; therefore there must be a fire" (1967, p. 361).) Thus, while it surely appears that there must be an intimate connection between the two (note, for instance, Leite's remarks: "It would seem, at first blush, that the state of being justified can't be fully distinguished from considerations pertaining to the activity" (2004, p. 219)), one might still plausibly claim that doxastic justification requires only the latter in the first instance (more on this below).

${ }^{6}$ The nature of the epistemic basing relation is, as is well known, a central problem of epistemology. Its centrality stems mostly from the fact that propositional knowledge requires not only propositional justification but also doxastic justification and the latter is something that can only be correctly ascribed
} 
forms a particular belief that $\mathrm{P}$ must be structurally similar to the way in which $\mathrm{P}$ is propositionally justified for $\mathrm{S}$. Suppose that $\mathrm{S}$ is doxastically justified in believing that $\mathrm{P}$, and suppose that $\mathrm{P}$ is propositionally justified for $\mathrm{S}$ partly because there is a proposition, $\mathrm{R}_{2}$, available to $\mathrm{S}$ that supports $\mathrm{R}_{1}$, which in turn supports $\mathrm{P}$. Then the idea is that it follows from these facts about $\mathrm{S}$ that $\mathrm{S}$ "arrives at" the belief that $\mathrm{P}$ on the basis of an inferential (or 'logical' in Firth's sense) path from $\mathrm{R}_{2}$ to $\mathrm{R}_{1}$ to $\mathrm{P}^{7}$

What I call the structural similarity constraint will play an important role in my argument against Klein's defense of infinitism, so let me hasten to point out that Klein (2007) actually agrees with the constraint and even offers a slogan-version statement of it when he writes, (PAR) "Doxastic justification is parasitic on propositional justification" (p. 8). I will assume below that (PAR) is true. ${ }^{8}$

There are now two further distinctions that need to be drawn in order for our assessment of Klein's epistemic infinitism not to miss the mark. The first distinction is among being justified, being able to justify, and having engaged in the activity of justifying (offering reasons in conversation or sotto voce). It is clear that a proposition's being justified for a subject does not require that the subject be able to justify or actually engage in the activity of justifying: propositional justification requires neither. It is somewhat less clear whether the subject might be doxastically justified in believing a proposition without being able to justify it or without having actually gone through the process of offering reasons for believing the proposition.

\footnotetext{
to a belief if it is based on the former. For an excellent survey of the contemporary literature on the epistemic basing relation, see Korcz (2015). For the purposes of this paper, the question regarding the nature of the basing relation can be safely set aside. I will rather try to clarify below how Klein understands doxastic justification and a fortiori the basing relation.

${ }^{7}$ Note also what Moser writes: "Propositional justification is basic to doxastic justification in the sense that one's having propositional justification is a necessary condition of one's having doxastic justification. Thus, if a person is justified in believing a proposition, then that proposition is justified for him. Doxastic justification, roughly speaking, is justification that depends on the manner in which one's beliefs are related to the conditions of propositional justification" (1984, p. 196, emphasis mine).

${ }^{8}$ For an illuminating discussion of the relation between propositional and doxastic justification, see Turri (2010b).
} 
There are at least three possible options here. One is that doxastic justification requires neither having the ability to offer reasons nor having actually gone through the process of offering reasons. ${ }^{9}$ Another is that that doxastic justification requires one's having the ability to offer reasons under appropriate circumstances (e.g., when a worry pertaining to the justificatory status of a belief is explicitly raised) but not necessarily having exercised that ability. And, the final option is that doxastic justification requires having engaged in the activity of offering reasons.

The second distinction concerns the last option in the three-fold distinction just mentioned. Suppose that doxastic justification requires having engaged in the activity of offering reasons. Now the question is whether the subject can be doxastically justified in having a certain belief only if she comes to hold (or, as Firth says, "arrives at") the belief as a result of being engaged in the activity of offering reasons. Firth's answer to this question appears to be "yes", as is evidenced by his remarks quoted above. ${ }^{10,11}$ However, one might also claim that the

\footnotetext{
${ }^{9}$ An intuitive problem with this option is that it seems to undermine the very distinction between propositional and doxastic justification. What can possibly distinguish doxastic from propositional justification if doxastic justification does not even require the ability to offer reasons in favor of a belief? However, the issue is not so easily settled. For a defense of the idea that doxastic justification does not even require such an ability, see Harman (1970), a seminal work which is mainly responsible for the establishment of what Leite (2004, p. 221) somewhat pejoratively calls the spectatorial conception of justification.

${ }^{10}$ A distinction relevant to the discussion here is the one Goldman draws between ex post justification and ex ante justification. Goldman (1979) writes: "Let us distinguish two uses of justified: an ex post use and an ex ante use. The ex post use occurs when there exists a belief, and we say of that belief that it is (or isn't) justified. The ex ante use occurs when no such belief exists, or when we wish to ignore the question of whether such a belief exists. Here we say of the person, independent of his doxastic state vis-à-vis $p$, that $p$ is (or isn't) suitable for him to believe" (p. 22). As Goldman further rightly notes, "The distinction between ex post and ex ante justifiedness is similar to Firth's distinction between doxastic and propositional warrant" (p. 23, fn. 17). Note that according to the reliabilist analysis Goldman offers in the paper, the ex post justification of a belief is, roughly, a function of the reliability of the operation that causes or produces it, one by the application of which the subject arrives at or comes to hold it. If this is so, then given (a strong reading of) the "similarity" between ex post and doxastic justification, Goldman's reliabilism takes it for granted that doxastic justification is a matter of how a given belief is arrived at.

${ }^{11}$ The problems that afflict a view like this are nicely documented in Evans (2013). Doxastic justification is, roughly, propositional justification plus the basing relation. So, the view at hand holds that a particular belief's being based on reasons requires the subject's arriving at that belief as a result of being engaged in the activity of offering reasons. However, according to Evans, such a view cannot account for such phenomena as what he calls backward basing, basing termination, and unconscious basing. Just take
} 
way in which the subject arrives at the belief is not relevant to whether she is doxastically justified in having the belief: what matters is, one might argue, whether she has actually gone through the process of justifying, regardless of whether her having the belief results from her having actually gone through that process. So, on this alternative, the subject that comes to hold a certain belief without engaging in the activity of offering reasons might still be doxastically justified in having that belief if she engages in that activity at a time after coming to hold that belief.

Given these different options regarding the nature of doxastic justification, it is clear that there are various different versions of epistemic infinitism about doxastic justification. I am not concerned in this paper with which of the options specified above is preferable but with which of those options Klein actually prefers. Klein explicitly holds that doxastic justification requires having actually engaged in the activity of justifying. Klein writes: "[Infinitism] is committed to an account of doxastic justification such that a belief is doxastically justified for $\mathrm{S}$ iff $\mathrm{S}$ has engaged in tracing the reasons in virtue of which the proposition $\mathrm{p}$ is justified..." (2007a, p. 11). ${ }^{12}$ Furthermore, according to Klein, the causal story about how a particular subject comes to hold ("arrive at") a belief is not (or at least need not be) relevant to whether the subject is doxastically justified in having that belief (and, this is where Klein parts company with Firth's conception of doxastic justification). Klein writes: "[What] lies at the heart of the infinitist's requirement for our doxastic justification [is] that we be able to produce reasons for

the first one, backward basing, the main thrust of which is captured by Evan's following remarks: "One of the bases of a belief might have been unavailable when the belief was originally formed" (p. 2946). If there is such a thing as backward basing, then a given belief might be properly based on reasons without the subject's arriving at that belief as a result of being engaged in the activity of offering reasons. 12 The part omitted with ellipsis in this quotation speaks for Klein's contextualism about doxastic justification and fully reads as "far forward enough to satisfy the contextually determined standards" ( $p$. 11). This aspect of Klein's infinitism will be discussed later in the paper. Note also Klein's following remarks: "[I]nfinitism holds that a particular belief is doxastically justified (at least to some degree) only if there is an available reason and we cite that reason as a reason for our belief" (2007b, p. 26, emphasis mine). 
our beliefs. The issue is not what causes our beliefs; but rather whether we can cite a reason for our beliefs" (2007a, p. 12).

In light of the distinctions above, it is now the right time to formulate a version of epistemic infinitism, a version which one might be naturally inclined to attribute to Klein on account of some of his explicit avowals like the ones just quoted. It is clear that infinitism needs to offer an account of doxastic justification as well as an account of propositional justification. Epistemic infinitism about propositional justification (or simply "propositional infinitism") holds that a proposition, $\mathrm{P}$, is justified for a subject, $\mathrm{S}$, only if there is an infinite and nonrepeating sequence of propositions available to $\mathrm{S}$ such that the first member, $\mathrm{R}_{1}$, supports $\mathrm{P}$ and the second member, $\mathrm{R}_{2}$, supports $\mathrm{R}_{1}$, and so on to infinity. Assuming that (PAR) is true, the account epistemic infinitism offers for doxastic justification must be similar in structure to the account it offers for propositional justification. So, if doxastic justification requires that the subject has engaged in the activity of justifying, as Klein holds it does, then infinitism about doxastic justification (or simply "doxastic infinitism") turns out to be committed to holding something along the following lines: a subject, $\mathrm{S}$, is doxastically justified in believing that $\mathrm{P}$ only if $\mathrm{S}$ has engaged in the activity of justifying $\mathrm{P}$, which involves (or simply is) the activity of tracing an endless inferential path that is structurally similar to the path through which $\mathrm{P}$ is propositionally justified for S.

There are at least two basic traditional reasons for rejecting epistemic infinitism characterized along the lines above. One appeals to the fact that human minds are finite, which means that we, as Aristotle puts it, "cannot traverse an infinite series" (1941, 72b10) in a finite amount of time available to us, given that each step in the "traversing" takes some time. This objection from finite minds clearly targets doxastic infinitism since doxastic justification, but 
not propositional justification, requires actually tracing or traversing an inferential path. ${ }^{13}$ The other reason against epistemic infinitism appeals to the fact that if infinitism is true, then the regress of propositions has "no starting point." A classic formulation of this "no starting point" objection is to be found in Sextus Empiricus's Outlines of Pyrrhonnism:

The Mode [of reasoning] based upon the regress ad infinitum is that whereby we assert the thing adduced as a proof of the matter needs a further proof, and this again another, and so on $a d$ infinitum, so that the consequence is suspension, as we possess no starting point for our argument. (1976, p. 166)

This is primarily an objection against propositional infinitism (and secondarily, given (PAR), against doxastic infinitism). The problem here is how propositional justification can possibly arise if propositional justification, as infinitism claims, requires an infinite evidential chain of reasons, one without a stopping (or starting!) point. ${ }^{14}$

In what follows, I will present and discuss an argument against propositional infinitism, an argument which attempts to articulate the very insight that the no-starting-point objection purports to spell out. As we will see, there are various responses to be found in Klein's works to the objection I will raise. ${ }^{15}$ My aim is to show that none of those responses can be plausibly

\footnotetext{
${ }^{13}$ As Aikin (2005) notes, there are actually two versions of the finite minds argument. One rests on the premise that "to run the regress of justification, [the subject] would need infinite time (because the inferences take time to make)", and the other on the premise that "to run the regress of justification, [the subject] would need an infinite number of beliefs (since those beliefs can't just get recycled)" (p. 202). Aristotle's version of the argument is clearly the former. The distinction between these two versions plays no substantial role below.

${ }^{14}$ The distinction here between arguments against propositional and doxastic infinitism corresponds, roughly, to Aikin's (2005, p. 192) distinction between "conceptual" and "ought-implies-can" arguments against infinitism.

${ }^{15}$ The central aim of this paper is to answer the question of whether Klein provides an adequate response to the argument that I will specify below. To achieve this aim, it is not necessary to delve into the arguments Klein adduces to motive epistemic infinitism. However, the issue is still interesting enough to justify some digression. Klein offers two main arguments to support infinitism. One stems from the purported plausibility of two principles. The principles are what Klein (1999, p. 298-9) calls the "Principle of Avoiding Circularity" (PAC) and the "Principle of Avoiding Arbitrariness" (PAA). PAC is the thesis that for all $\mathrm{x}$, if a person, $\mathrm{S}$, has a justification for $\mathrm{x}$, then for all $\mathrm{y}$, if $\mathrm{y}$ is in the evidential ancestry of $\mathrm{x}$ for $\mathrm{S}$, then $\mathrm{x}$ is not in the evidential ancestry of $\mathrm{y}$ for S. PAA is the thesis that for all $\mathrm{x}$, if a person, $\mathrm{S}$, has a justification for $\mathrm{x}$, then there is some reason, $\mathrm{r}_{1}$, available to $\mathrm{S}$ for $\mathrm{x}$; and there is some reason, $r_{2}$, available to $S$ for $r_{1}$; etc. According to Klein, the combination of these principles captures "the well-founded intuition that arbitrary beliefs, beliefs for which no reason is available, should be avoided" (p. 299) and "entails that the evidential ancestry of a justified belief be infinite and nonrepeating" (p. 299). The second argument Klein offers for infinitism is an argument from elimination more specifically, that foundationalism and coherentism face insurmountable problems while the
} 
held without infinitism losing its title to being a non-skeptical account of justification, an adequacy constraint on which is to deliver non-skeptical results for propositional and doxastic justification. $^{16}$

\section{The Argument from the Conditionality of Inferential Justification}

The argument I will discuss against epistemic infinitism is an old one, various versions of which have been offered by a number of philosophers in the past. ${ }^{17}$ I hope to present a clear articulation of one of its stronger versions by explicitly stating some of its central presuppositions. When responding to a version of this argument in one of his earlier defenses of infinitism, Klein notes that "This is the most difficult objection to answer because it is the most difficult to fully understand" (1999, p. 312). This section will hopefully help to allay some worries such as Klein's pertaining to the obscurity of the argument.

The argument I have in mind takes its cue from a central thesis that gives rise to the well-known epistemic regress problem. The epistemic regress problem starts with the observation that some beliefs are inferentially justified: some beliefs are such that, barring circular reasoning, their justification requires the evidential support of some other beliefs. For instance, my belief in the proposition that my wife is back home from the gym class receives its justificatory support (at least in part) from my belief in the proposition that her car is parked

proposed objections to infinitism fail. Here is, roughly, what I think about these arguments. The argument from (PAA) and (PAC) to infinitism works only if it assumes that having a reason for a proposition (understood as the object of belief) just means there being another proposition available to the subject from which the proposition in question can be properly inferred (see Ginet 2005a, p. 143); however, if that is so, the argument begs the question against the foundationalist. The argument from the elimination of alternatives is as suspect as any argument from elimination: a defender of one of those alternative views can rightly contest that the proposed objections to their views are not insurmountable at all.

${ }^{16}$ Klein explicitly holds that epistemic infinitism is "the only viable, non-skeptical response" (2011, p. $245)$ to and "it can solve" $(2014$, p. 96) the famous epistemic regress problem, a version of which will be presented below. It needs to be emphasized, however, that Klein also stresses at various points that the question of whether epistemic infinitism is an adequate account of justification (i.e. whether it correctly describes the normative rules governing the notion of justification) needs to be distinguished from the question of whether it offers a non-skeptical stance (see for instance Klein (1998, p. 922)): the answer to the former might well be "yes" while the answer to the latter is "no". In this paper, I am more interested in the latter than the former.

${ }^{17}$ See Clark (1988), Moser (1985), Alston (1985), Kajamies (2009). 
outside our house. Now, the thesis that gives rise to the epistemic regress problem is that a belief state with a certain content can have a justificatory power that might be transmitted to a different belief with a different content state if that (former) state itself is justified. Let us call the belief whose epistemic status is initially questioned the target belief, the belief(s) that is (are) intended to provide justificatory support for the target belief the supporting belief(s). The thesis is that a supporting belief can provide justificatory support for the target belief only if that supporting belief itself is justificatorily supported: if the supporting belief does not receive justificatory support, then neither the target belief nor that supporting belief can be considered as being justified. If this thesis is not mistaken, then there are four possibilities that concern the regress of epistemic justification, on the assumption that either only inferentially justified beliefs can be justified or some beliefs can be non-inferentially justified. If only inferentially justified beliefs are justified, then the regress of epistemic justification might either terminate with unjustified beliefs or circle back on itself or go on indefinitely. If some beliefs can be noninferentially justified, then the regress of epistemic justification might terminate with noninferentially justified beliefs. The epistemic regress problem is, as it is commonly conceived, whether any of these four possibilities is a viable option, one that rationally silence the skeptic that argues otherwise.

It is natural to view the epistemic regress problem as a problem for doxastic justification on the grounds that the regress is generally initiated by raising a question of the form "why do you believe that P?" to a particular subject and the subject's ensuing engagement in the activity of locating and citing reasons for her belief can only be plausibly taken as a requirement for her being doxastically justified in having that belief. However, the epistemic regress problem can also be construed as a problem for propositional justification. Let us call the content of the belief whose initial credibility is question the target proposition, and the content(s) of that (those) beliefs that provide justificatory support for the target proposition the supporting 
proposition $(s)$. Now, a natural analogue of the thesis that gives rise to the regress problem for doxastic justification can be formulated as follows: if the supporting proposition does not receive justificatory support, then neither the target proposition nor that supporting proposition can be considered as being justified. And, this thesis leads to four distinct possibilities for propositional justification corresponding to the ones specified above.

The central idea I am interested in here is the conditional character of inferential justification. As for propositional justification, we can say this: a proposition, $\mathrm{R}_{1}$, might justify another proposition, $\mathrm{P}$, via an acceptable path of inference (for a given subject) if, and only if, $\mathrm{R}_{1}$ itself is justified (for the subject). ${ }^{18}$ If $\mathrm{R}_{1}$ is not justified, then $\mathrm{P}$ cannot be propositionally justified for the subject on the basis of there being an acceptable inferential path from $\mathrm{R}_{1}$ to $\mathrm{P}$ : the fact that there is an acceptable inferential route from $\mathrm{R}_{1}$ to $\mathrm{P}$ by itself suffices to justify neither $\mathrm{R}_{1}$ nor $\mathrm{P}$ (but at most suffices to justify, e.g., the conditional proposition that if $\mathrm{R}_{1}$ then P). And, as for doxastic justification, we can say this: a belief with the content $R_{1}$ can be justified by being properly inferred from some other belief with the content $\mathrm{P}$ if, and only if, that other belief is itself justified. If the subject's belief that $R_{1}$ is not justified, then her belief that $\mathrm{P}$ cannot be doxastically justified on the basis of her making an acceptable inference from $\mathrm{R}_{1}$ to $\mathrm{P}$ : the fact that she makes such an inference by itself suffices to justify neither the belief that $\mathrm{R}_{1}$ nor the belief that $\mathrm{P}$ (but at most suffices to justify, e.g., the belief that if $\mathrm{R}_{1}$ then $\mathrm{P}$ ). ${ }^{19}$ So, we arrive at the following principles:

\footnotetext{
${ }^{18}$ Let me make two points about the biconditional character of this thesis. First, $\mathrm{R}_{1}$ 's being justified is a sufficient condition for P's being justified for the subject on the basis of there being an acceptable path of inference from the former to the latter only on the condition that $\mathrm{R}_{1}$ is undefeated by any other propositions that subject believes. Second, $\mathrm{R}_{1}$ 's being justified is a necessary condition for P's being justified for the subject on the basis of there being an acceptable path of inference from the former to the latter only on the condition that there are no other propositions than $\mathrm{R}_{1}$ such that the subject believes them and there is an acceptable path of inference from those propositions to $\mathrm{P}$. The thesis should be read with these qualifications in mind.

${ }^{19}$ The central idea operative here is nicely captured by Dancy's (1985) following remarks: "When we justify belief A by appeal to beliefs B and C, we have not yet shown A to be justified. We have only shown that it is justified if $B$ and $C$ are. Justification by inference is conditional justification only; A's justification is conditional upon the justification of B and C" (p. 55).
} 
(IJC) Inferential propositional justification is conditional justification (i.e., if there is an acceptable inferential path from $\mathrm{R}_{1}$ to $\mathrm{P}$, then $\mathrm{P}$ is justified if (and only if) $\mathrm{R}_{1}$ is). ${ }^{20}$

(IJC*) Inferential doxastic justification is conditional justification (i.e., if the subject makes an acceptable inference from her belief with the content $R_{1}$ to her belief with the content $\mathrm{P}$, where $\mathrm{R}_{1}$ is a good reason for holding $\mathrm{P}$, then the subject's believing that $\mathrm{P}$ is justified if (and only if) the subject's believing that $\mathrm{R}_{1}$ is justified). ${ }^{21}$

If (IJC) is true, then given that a proposition's being conditionally justified is not the same as its being actually justified, a proposition's being inferentially justified is not the same as its being actually justified. And, if (IJC*) is true, then given that a belief's being conditionally justified is not the same as its being actually justified, a belief's being inferentially justified is not the same as its being actually justified. The argument that I will present below against epistemic infinitism is primarily an objection against propositional infinitism and therefore is based on (IJC). Therefore, in the remainder of this section, I will be focusing on (IJC) rather than (IJC*). Klein's take on both (IJC) and (IJC*) will be examined in the next section.

\footnotetext{
${ }^{20}$ Conditional properties (e.g., in our case, conditional justification) are, on a standard conception, properties the instantiation of which by a particular entity does not merely (materially) imply but is dependent upon their instantiations by some other entities. Clark writes: "The underlying intuition, of course, is that anything whose existence not merely implies but is exclusively dependent upon an infinite succession of similar elements for which there is no independent existence proof does not after all exist. It does not flatly, categorically exist. It only conditionally does so" (1988, p. 372). After noting that "we lack resources within standard logic for distinguishing implication and dependence" (1988, p. 373), Clark moves on to providing an account of the notion of dependence in question. Dependence is a stronger relation than mere (material) implication: the former entails the latter but not vice versa. It is reasonably clear that regresses that stem from mere implication are not problematic. A plausible explanation of why the "regress" of numbers is not especially problematic is that it is merely a regress of implication relations: 1 is a number only if 2 is a number, 2 is a number only if 3 is a number, and so on. 1's being a number does not depend, in the relevant sense, on 2's being a number but merely (materially) implies it. The regresses generated by implication entail the existence of the infinite number of objects involved in those regresses; however, the regresses generated by dependence appear to entail that none of the objects involved in those regresses can possibly exist.

For the purposes of this paper, I will assume an intuitive understanding of the notion of dependence. For more discussion on the issue, see Gillett (2003).

${ }^{21}$ Moser's following remarks are worth noting here: "My main contention.... is that the correct way to portray the infinitist's non-circular infinite justificatory regress in which every member, including its terminus $e_{0}$, is purportedly justified by the next member (and not by any external information) is as follows:
}

$$
\ldots, \text { if justified } e_{n} \text { justifies } e_{n-1}, \ldots, \text { if justified } e_{1} \text { justifies } e_{0} . ”(1985, \text { p. 70) }
$$


In order to get a better grasp of the conditional character of inferential propositional justification, it might help to draw an analogy with the notion of instrumental value. The value of some of our actions derives solely from their being a means to achieve certain aims. There might be nothing valuable in and of itself in eating more vegetables than one usually does, and the value such an action has derives from its being a means to achieve, say, the aim of being healthier, which in turn might be considered as deriving whatever value it has from its being a means to achieve still a further aim, something like having a longer and more productive life. The point that is of concern to us is that the value an action has in virtue of its being a means to an end is only conditional value: a certain means to a certain end has value just in case the end has value. If the end does not have any value, then the mere fact that the end can be effectively realized by a certain means does not render that means valuable. The same goes for inferential justification. If the supporting proposition is unjustified (or does not have any "epistemic value or merit") for a subject, then the mere fact that the target proposition can be correctly inferred from the supporting proposition does not render the target proposition justified for that subject.

What reason do we have to think that (IJC) is true? Why cannot the justification of a target proposition by inference from a supporting proposition be actual justification, the sort of justification an awareness of which entitles us to claim that the target proposition is justified? The answer is, as Ginet succinctly puts it, that "Inference cannot originate justification, it can only transfer it from premises to conclusion" (2005a, p. 148, emphasis original). ${ }^{22,23}$ According

\footnotetext{
${ }^{22}$ Compare what Aristotle writes in the Posterior Analytics: "Now since the required ground of our knowledge... of a fact is the possession of such a syllogism as we call demonstration, and the ground of the syllogism is the facts constituting its premisses, we must not only know the primary premisses...beforehand, but know them better than the conclusion: for the cause of an attribute's inheritance in a subject always inheres in the subject more fully than the attribute...So, since the primary premisses are the cause of our knowledge...it follows that we know them better...than their consequences, precisely because our knowledge of the latter is the effect of our knowledge of the premisses" (1941, 72b25-33, quoted by Klein (2014, p. 104)).

${ }^{23}$ Klein (2011, p. 248) explicitly divides the (complex) thesis expressed by Ginet into its simpler components, naming one Non-Originating Principle ("Reasoning, alone, cannot produce epistemic warrant") and the other Inheritance Principle ("Reasoning can transmit the requisite epistemic warrant for knowledge from other beliefs"). According to Klein, these are "two core presuppositions underlying
} 
to this answer, questions about the source or origin of justification need to be distinguished from questions about the transmission of justification. Inferential relations among propositions, however strong or pervasive they might be, can only pertain to the latter and never by themselves enable one to answer the former. This means that a solution to the problem of the origin of actual justification (the problem of how justification emerges or is generated in the first place) requires an account that cannot solely be based on the presence or strength of inferential relations.

At this point in the dialectic, one might reasonably question why inference by itself cannot be the source of actual justification. This question is intimately tied to another question, one that concerns the primary bearer or unit of actual justification: are the primary bearers of justification individual propositions or the systems of propositions (which are, roughly, sets of individual propositions among which there are inferential connections to a certain degree)? Does the justificatory status of a system of propositions derive from the justification (at least some of) the individual propositions that are part of that system have in isolation? Or does the justificatory status of an individual proposition derive in some way from the way in which that proposition is related to some other propositions in the system of which it is a part? Presumably, the primary bearer of justification is where we should look for the source of justification. So, if the primary bearer of justification were systems of propositions rather than individual propositions, then they would be so in virtue of that feature that relevantly distinguishes them from individual propositions that comprise them, which is evidently their involving certain inferential relations among those individual propositions. This means that if systems of propositions were the primary bearer of justification, then barring skepticism, they would be the source of justification in virtue of there being certain inferential relations among individual

the regress argument as put forth by foundationalists without which the argument could not succeed" (p. 248). 
propositions that comprise them. So, the idea that inference by itself cannot be the source of justification seems to receive its support from the idea that systems of propositions are not the primary bearer of justification because if they were, then a non-skeptical alternative would tell us that they can also be the source of justification in virtue of inferential connections among individual propositions that comprise them.

Let's take stock. The epistemic regress argument rests on (IJC), the thesis that inferential justification is only conditional justification: there being an inferential path from a supporting proposition to a target proposition justifies neither, but would justify the former if (and only if) the latter were itself justified. (IJC) is supported by the thesis that inference by itself cannot generate but only transmit justification, which in turn appears to presuppose that the primary bearer of justification is individual propositions but not systems of individual propositions.

If (IJC) is true, then there is a straightforward argument against infinitism. Infinitism holds that a given proposition $\mathrm{P}$ is justified for $\mathrm{S}$ only if there is an endless series of nonrepeating propositions available to $\mathrm{S}$ such that beginning with $\mathrm{P}$, each succeeding member is inferable via an acceptable route of inference from the immediately preceding one. If this is so, however, given (IJC), propositions can, on infinitism, be only conditionally but not actually justified. If the structure of justification is infinite and non-repeating, as infinitism insists, then the most we can have is conditional justification for propositions that are constituents of that infinite structure: given the infinity of the structure, the "if" is never eliminated. If this is so, then contra Klein, infinitism is not a non-skeptical alternative to foundationalism and coherentism, given that skepticism can only be silenced if some propositions we believe in are actually justified. Call this the argument from the conditionality of inferential justification (or simply the argument from conditionality). ${ }^{24}$

\footnotetext{
${ }^{24}$ Kajamies's (2009) observations are relevant here: “There is something very appealing about the view that incurably conditional support is not genuine support. If the support for each proposition $P_{\mathrm{x}}$ in [an infinite] sequence is incurably conditional, i.e. if its each proposition is conditionally supported by its successor, no satisfactory answer can be reached as to whether these conditions are satisfied [i.e. whether
} 


\section{Klein's Responses to the Argument from Conditionality}

The first response that Klein gives to the argument from conditionality starts with a restatement of the argument in terms of "provisional justification." According to Klein, the argument from conditionality succeeds in establishing that "if all justification is provisional, no belief becomes unprovisionally justified” (1999, p. 313). Klein's reason for preferring "provisional” over Dancy's "conditional" is that "the term "provisional" more clearly underscores the fact that the reasons in the chains are replaceable" (1999, p. 324, fn. 53). In view of this rephrasing of the original argument, Klein argues that the conclusion of the argument from conditionality - that “every proposition is only provisionally justified" $(1999$, p. 313$)$ - is problematic just in case it is required that "reasoning settle matters once and for all" (1999, p. 313). Since that requirement is what infinitism as such is clearly committed to deny, the argument from conditionality simply begs the question against infinitism by insisting that without the elimination of the conditionality of inferential justification, a proposition cannot be actually justified via there being acceptable inferences from other propositions to that proposition.

This response misses the point of the argument from conditionality, and this is because Klein's replacing "conditional" by "provisional" is not innocuous. What is it for reasoning to "settle matters once and for all"? The phrase "once and for all" is surely reminiscent of a Cartesian yearning for such high epistemic virtues as "certainty," "infallibility" or "incorrigibility"; and, Klein's ensuing defense of this response to the argument from conditionality confirms that this is what he has in mind. Klein writes: "I readily grant that the kind of final guarantee that Descartes and others have sought is not available if infinitism is correct" $(1999$, p. 313). If this is what we are to understand from the requirement that reasoning settle matters once and for all, then provisional justification in Klein's sense amounts to

any of those propositions in the sequence is genuinely supported], even in principle...I believe that we have a deep intuition according to which the question 'Is $P_{\mathrm{i}}$ supported?' cannot be satisfactorily answered by 'Yes it is if $P_{\mathrm{j}}$ is supported'. We should be able to reach... a 'Yes' or a 'No', but no such answer is reachable if the support for each $P_{\mathrm{x}}$ is incurably conditional" (pp. 531-2). 
defeasible justification, the sort of justification that can be defeated by further evidence. ${ }^{25}$ This is because only under this understanding, provisional justification might turn out to be problematic given the requirement that reasoning produce final guarantees of the sort Descartes has sought. However, the argument from conditionality does not purport to establish that infinitism entails that every proposition is only defeasibly justified but that every proposition is conditionally justified. The difference is that a proposition that is only defeasibly justified is still actually justified, though only to a degree that falls short of Cartesian certainty, while a proposition that is conditionally justified is not actually justified. The idea is that inferential justification by itself does not give rise to actual justification, whether it be defeasible or indefeasible. A defender of the argument from conditionality might readily grant that the search for Cartesian final guarantees is misguided and that propositions can only be defeasibly justified but still argue that the fact that infinitism is committed to there being no propositions that are not conditionally justified is problematic for that view, and this is so even if we agree with Klein that the reasons in the evidential ancestry of a target proposition are "replaceable."

Klein's second response to the argument from conditionality specifies the sort of infinitism that he is committed to by emphasizing that the primary bearers of justification are not individual propositions but systems of propositions. Klein writes:

The infinitist conception of propositional justification...conceives of justification of a proposition, $p$, as emerging when the set of reasons for $p$ is non-repeating and endless...A proposition is justified in virtue of being a member of a set of propositions of a given sort. (2007a, p. 8)

Klein calls this version of infinitism "warrant-emergent infinitism" (2005a, p. 136). Warrantemergent infinitism contrasts with "warrant-transfer infinitism" (2005a, p. 135), which thinks of propositional justification as a property that is primarily attached to individual propositions and transferable to other individual propositions. Given this distinction at hand, it seems that the argument from conditionality can work only against warrant-transfer infinitism but cuts no

\footnotetext{
${ }^{25}$ This point has also been made by Ginet (2005a).
} 
ice with warrant-emergent infinitism. If propositional justification is a property the primary bearer of which is infinite sets of propositions inferentially arranged in a certain way, as warrant-emergent infinitism claims it to be, then contra what the argument from conditionality presupposes, there does not seem to be any principled reason to deny that inference can originate justification, given that it is presumably in virtue of there being inferential connections that hold among its members that infinite sets of propositions are bearers of justification. Furthermore, if inference can originate justification, as warrant-emergent infinitism appears to imply, then contra (IJC), a proposition that is a member of a set of propositions that are inferentially connected to each other can be actually justified solely in virtue of being a member of that set. Therefore, if (IJC) is rejected by warrant-emergent infinitism, then that form of infinitism simply goes untouched by the argument from conditionality one of whose central assumptions is (IJC).

Klein's warrant-emergent infinitism is a view about the origin of propositional justification, according to which propositional justification is not a property that can be transmitted from one proposition to another but rather is a property that emerges whenever there is an endless, non-repeating set of propositions available as reasons. To capture more precisely what this view is about, let us call it warrant-emergent propositional infinitism. If this view is correct, then there is no need for an account of how warrant is transferred simply because there is no such thing as warrant transfer - the only interesting relevant issue that remains is to explain how warrant emerges. Furthermore, on this sort of infinitism, a target proposition, P, is not justified for the subject $\mathrm{S}$ in virtue of there being another proposition, $\mathrm{R}_{1}$, available to $\mathrm{S}$ from which $\mathrm{P}$ can be correctly inferred. The idea that the justification of $\mathrm{P}$ depends on there being an acceptable inferential path from $\mathrm{R}_{1}$ to $\mathrm{P}$ in the way implied by the in-virtue-of relation assumes that justification is something that is transferred from one proposition to another, and in that case, the argument from conditionality applies in its full force. Rather, warrant-emergent 
infinitism holds that $\mathrm{P}$ is justified for $\mathrm{S}$ only if there is another proposition, $\mathrm{R}_{1}$, available to $\mathrm{S}$, from which $\mathrm{P}$ can be correctly inferred (and $\mathrm{R}_{1}$ is justified for $\mathrm{S}$ only if there is another proposition $\mathrm{R}_{2}$, available to $\mathrm{S}$, from which $\mathrm{R}_{1}$ can be correctly inferred, and so on). The point is, as Klein notes, that "“"A holds only if B holds" can be true without "A holds in virtue of B holding" being true" (2003, p. 722); and, if this is so, then "Being justified...is not a troublesome dependent property because a proposition being justified...does not arise in virtue of another proposition being justified - a proposition is justified for $\mathrm{S}$ in virtue of being a member of a set of propositions each member having the required properties" (2003, p. 723).

I agree that this response defuses whatever force the argument from conditionality is supposed to have against infinitism. Warrant-emergent propositional infinitism rejects (IJC) because it holds that mere inferential relations among a set of propositions appropriately structured might provide the holistic basis for the emergence of actual justification and thus need not be conceived as supporting mere conditional justification. On this view, inferential relations among a finite number of individual propositions (say, the inferential relation between two propositions, $\mathrm{P}$ and $\mathrm{R}_{1}$ ) does not only fail to provide actual justification but also fail to provide conditional justification. On warrant-emergent propositional infinitism, propositional justification, be it actual or conditional, does not emerge at all among a set of finite number of individual propositions among which there are inferential relations. So, at the level of sets consisting of finite number of propositions, (IJC) is false because there is no such thing as inferential propositional justification at that level. And, at the level of sets consisting of infinite number of propositions, (IJC) is again false because actual justification might emerge out of inferential relations at that level.

The question that I want to raise now is whether Klein's warrant-emergent infinitism is a non-skeptical alternative, and my answer is in the negative. If inferential relations among a finite set of propositions do not suffice for the emergence of propositional justification for those 
propositions, then the same must also go for doxastic justification, assuming (PAR) (i.e., the thesis that doxastic justification is parasitic on propositional justification) is, as Klein agrees, true: if propositional justification emerges only at infinity, doxastic justification must also emerge only at infinity. Assuming that doxastic justification requires, as Klein agrees, that one has actually traced an inferential path, what one gets by combining warrant-emergent propositional infinitism and (PAR) is what I shall call warrant-emergent doxastic infinitism, according to which doxastic justification for believing a proposition emerges only when the subject has completed tracing the infinite sequence of reasons in virtue of which that proposition is propositionally justified (more on this below). Now, given that tracing an inferential path takes time, which entails that it is not possible that we qua finite beings complete tracing an infinite sequence of reasons, warrant-emergent doxastic infinitism entails that we are not justified in believing any propositions, and skepticism wins the day.

Interestingly, however, despite the fact that Klein endorses warrant-emergent propositional infinitism and (PAR), he rejects warrant-emergent doxastic infinitism. This bring us to Klein's third response to the argument from conditionality, which can only be plausibly discussed by introducing the sort of contextualism he defends about doxastic justification. Klein writes:

The infinitist will take the belief that $p$ to be doxastically justified for $\mathrm{S}$ just in case $\mathrm{S}$ has engaged in providing "enough" reasons along an endless path of reasons. S would be completely doxastically justified if every reason in the path were provided. But assuming it takes some time to provide reasons, even though a proposition might be completely justified (if there is a suitable path of reasons), no belief could ever be completely doxastically justified...[A]s $\mathrm{S}$ engages in the process of providing reasons they become better justified...How far forward in providing reasons $\mathrm{S}$ need go seems to me to be a matter of the pragmatic features of the epistemic context...(2007a, p. 10)

According to Klein's contextualism about doxastic justification, then, one does not need to finish the infinite process of offering reasons for one's belief in order to be doxastically justified 
in having that belief but only need to trace a finite sequence of reasons, the 'length' of which is determined by some conversational and more broadly contextual factors. ${ }^{26}$

It is clear that the sort of contextualism Klein defends for doxastic justification is not (or is not consistent with) warrant-emergent doxastic infinitism. Klein explicitly rejects warrant-emergent doxastic infinitism when he writes: "An infinitist would seek to increase the doxastic justification for an initial belief -the belief requiring reasons- by calling forth more and more reasons. The more imbedded the initial belief, the greater its doxastic justification" (2007b, p. 26). According to Klein, contra warrant-emergent doxastic infinitism, the emergence of doxastic justification does not require that the subject "call forth" an infinite number of reasons.

What is perhaps less clear than Klein's rejection of warrant-emergent doxastic infinitism is that, on Klein's contextualism, it is not even required for a subject to be doxastically justified to some degree in holding a belief that she complete tracing a finite sequence of reasons, the 'length' of which is somehow determined by the context. Klein holds that the subject who has located some reasons for a belief without yet completely tracing the finite sequence of reasons required by the context is still doxastically justified to some degree. As Klein writes: "A belief is doxastically justified (at least to some degree) if we have located a good reason for holding it...I am making progress in increasing the doxastic justification of the original belief [the initial belief requiring reasons] when I locate more and more reasons for it" (2007b, p. 28, emphasis mine). Let us call the following view warrant-emergent doxastic finitism: doxastic justification for a belief in a proposition emerges only when the subject has completed tracing the finite sequence of reasons, the 'length' of which is determined by certain contextual parameters. The

\footnotetext{
${ }^{26}$ Klein's contextualism is not the more recent variety defended, for instance, by DeRose (1992) but is more akin to the old-fashioned variety defended by Annis (1978).
} 
point is that Klein rejects warrant-emergent doxastic finitism as well as warrant-emergent doxastic infinitism.

I would now like to focus on Klein's rejection of warrant-emergent doxastic infinitism. Consider the following triad: (i) warrant-emergent propositional infinitism is true, (ii) warrantemergent doxastic infinitism is false, (iii) (PAR) is true. It is because (i) and (iii) entail the falsity of (ii) that this triad is inconsistent. However, Klein explicitly endorses all the three. So, Klein's version of infinitism is not adequate.

Let me elaborate on this point. Warrant-emergent propositional infinitism is a view about the origin of propositional justification, and warrant-emergent doxastic infinitism is a view about the origin of doxastic justification. And, (PAR) is a thesis about the relation doxastic justification bears to propositional justification. Now, assuming that engaging in the activity of tracing an evidential path is required for doxastic justification, which Klein himself explicitly holds, (PAR) (or at least one of its suitable variants) tells us that the evidential path the subject must trace for doxastic justification to emerge is the same as the evidential path required for the emergence of propositional justification. And, warrant-emergent propositional infinitism holds that propositional justification emerges only when there is an infinite chain of reasons available to the subject, i.e., only when the evidential path is infinite. It follows from these theses that warrant-emergent doxastic infinitism is true, that doxastic justification emerges only when the subject has completed tracing the infinite evidential path required for the emergence of propositional justification. This shows that (i)-(iii) is an inconsistent triad. ${ }^{27}$

\footnotetext{
${ }^{27}$ Klein writes: "The infinitist, like the coherentist, takes propositional justification to be what I called an emergent property that arises in sets of propositions. In particular, the infinitist holds that propositional justification arises in sets of propositions with an infinite and non-repeating structure such that each new member serves as a reason for the preceding one. Consequently, an infinitist would seek to increase the doxastic justification for an initial belief - the belief requiring reasons - by calling forth more and more reasons. The more imbedded the initial belief, the greater its doxastic justification" (2007b, p. 26, emphasis mine). The reasoning here is a non-sequitur. If (PAR) is true, then what can plausibly derived from warrant-emergent propositional infinitism about doxastic justification is warrantemergent doxastic infinitism, according to which doxastic justification arises only if the subject has completed tracing the infinite evidential path 'laid out' by propositional justification.
} 
In order to avoid the inconsistency, one of the theses comprising the triad must be eschewed. A non-skeptic theory of justification cannot drop (ii) because there is a short way from warrant-emergent doxastic infinitism to skepticism on the evidently true assumption that producing and offering reasons takes time. So, a non-skeptic theory of justification needs to reject either (i) or (iii). Further, I take it that, for the sake of the argument, (PAR) can be safely assumed to be true, as it is an eminently plausible thesis and there is no indication in Klein's writings that might cast doubt on it. This leaves us with the option of rejecting (i).

Klein's main motivation for holding warrant-emergent propositional infinitism is that he believes that that view defuses the force of the argument from conditionality by discarding the central thesis that argument takes for granted, i.e. (IJC). However, as we have seen, warrantemergent propositional infinitism and (PAR) entail warrant-emergent doxastic infinitism, a thesis that the skeptic would happily endorse. Now, I do not think Klein needs warrant-emergent propositional infinitism in order to save epistemic infinitism from the objection raised by the argument from conditionality, so I think that Klein qua an infinitist is not committed to holding (i). Let me explain.

According to Klein, doxastic justification for a belief emerges as soon as we locate and cite even a single reason for having that belief. It needs to emphasized that, for Klein, this "is the case even if we have not yet located a reason for holding the (first) reason" (2007b, p. 28) for the target belief. Then, if engaging in "the process of locating and citing" reasons by itself originates doxastic justification, then Klein directly rejects (IJC*). And, it is because Klein rejects (IJC*) without embracing warrant-emergent doxastic infinitism, that an option available to Klein is to reject (IJC) without embracing warrant-emergent propositional infinitism (and being committed to the inconsistent triad above). That is, Klein can simply drop warrantemergent propositional infinitism and defend what one might call localized propositional infinitism, according to which propositional justification emerges 'locally' (at the level of a 
finitely long evidential chain of propositions) rather than 'holistically' (at the level of an infinitely long evidential chain of propositions): there is, on this view, propositional justification for a proposition as soon as there is a reason available to the subject for that proposition and that this is the case even if there is no reason available to the subject for that (first) reason. Like its holistic warrant-emergent cousin, localized propositional infinitism denies that an inferential path from one proposition to another cannot originate justification but only transfer it from one proposition to another. So, localized propositional infinitism is not what Klein calls warranttransfer infinitism. However, unlike its warrant-emergent cousin, localized propositional infinitism accepts that some degree of propositional warrant emerges when there are inferential relations among a finite set of propositions, the limiting case of which is one with two propositions. And, localized propositional infinitism is not vulnerable to the argument from conditionality since that sort of infinitism rejects the major premise of that argument, namely (IJC). ${ }^{28}$

The question that naturally arises is this: in virtue of which of its features localized propositional infinitism is a version of infinitism? This question is especially pressing given that view's commitment to the thesis that propositional justification emerges among a finite, inferentially structured chain of propositions. On this view, the degree of propositional justification increases as that chain gets longer: the more imbedded the target proposition, the

\footnotetext{
${ }^{28}$ The thesis that inference itself can create justification, which Turri (2014) calls inferential creationism, is, at least prima facie, very counterintuitive. Some of its implausible implications has been pointed by Ginet (2005) and Bergmann (2014). If inferential creationism is true, then, Ginet writes, "we seem to get the result that one could start with a belief (or sets of beliefs) that is totally unjustified, because it lacks any inferential justification, and by spinning out a long enough chain of inference from it reach a belief that has the degree of justification required for knowledge" (p. 155). In the similar vein, Bergmann writes: "Suppose you have two beliefs, B1 and B2, both of which are not justified at all, because neither of them is based on any reasons or evidence at all. And suppose also that B2 implies B1. Can B1 become justified to some degree solely in virtue of your later inferring it from the still unjustified belief B2, which implies it? It seems clear that the answer is "no."” (p. 43). For a defense of inferential creationism, see Turri (2014). Peijnenburg and Atkinson (2013) provides "a detailed procedure for the emergence of justification that enables us to see exactly how justification surfaces from a chain of reasons" (p. 546). My objection below to localized propositional infinitism is not directed to its commitment to inferential creationism: I will argue that even if we take inferential creationism for granted, localized propositional infinitism is beset by a serious problem.
} 
greater its degree of propositional justification. If this is so, however, then the degree of justification a proposition possesses relative to a subject might be great enough to entitle us to claim that that proposition is justified for that subject without there being an infinite chain of reasons available to her. ${ }^{29}$ If the degree of justification for a proposition increases as the chain in which that proposition is imbedded gets longer, then it is only to be expected that a finitely long chain of reasons will be sufficient for a proposition to earn the title "justified". What reason can one possibly have to insist that propositional infinitism is true if one insists that propositional justification emerges 'locally' in the sense above? ${ }^{30}$

Localized propositional infinitism involves a commitment to two different theses, one about the origin (and degree) and the other about the structure of propositional justification:

(L) Propositional justification for a proposition relative to a given subject emerges as soon as there is a reason available to the subject for that proposition, and the more

\footnotetext{
${ }^{29}$ Klein seems to agree when he writes: "Now, if knowledge required actually completing the series, knowledge would not be possible. But why suppose that knowledge requires the highest possible degree of warrant or absolutely credible belief? As the series lengthens, warrant or credibility increase. Nothing prevents it increasing to the degree required for knowledge" (2005a, p. 138).

${ }^{30}$ One might wonder whether the two principles, viz. (PAA) and (PAC), endorsed by Klein (1999) can provide independent motivation for the "infinitism" part of localized propositional infinitism that is rendered obsolete by the "localized" part. (My take on these two principles is briefly stated in fn. 15 above.) My answer is "no." What makes localized propositional infinitism localized in the relevant sense not only renders propositional infinitism pointless but is also in clear tension with (at least) one of Klein's two principles, namely (PAA). Localized propositional infinitism is the view that propositional justification for a proposition emerges as soon as there is a reason available to the subject for that proposition and this is the case even if there is no reason available to the subject for that (first) reason. And, PAA is the thesis that for all $\mathrm{x}$, if a person, $\mathrm{S}$, has justification for $\mathrm{x}$, then there is some reason $\mathrm{r}_{1}$, available to $S$ for $x$, and there is some reason, $r_{2}$, available to $S$ for $r_{1}$; and so on (Klein (1999, p. 299)). PAA holds, and localized propositional infinitism explicitly denies, that a necessary condition for there being propositional justification for a proposition is there being a reason available to the subject for the (first) reason that supports that proposition. So, if my thesis that the way Klein rejects warrant-emergent doxastic infinitism, combined with (PAR), commits him to localized propositional infinitism is not mistaken, then Klein needs to abandon (PAA). (An interesting fact is that Klein does not even mention (PAA) and (PAC) in his more recent expositions and defense of epistemic infinitism (see, e.g., (2011) and (2014)), those two principles that play such a central role in (1999), the paper that effectively started his infinitist crusade. I believe their sudden disappearance is telling, and my conjecture is that Klein is aware at some level of their tension with localized propositional infinitism that he is committed to.) Thanks to an anonymous reviewer for pressing on this issue.
} 
reasons available to the subject for a proposition the greater its degree of propositional justification.

(I) A proposition can be propositionally justified for a given subject only if there is an infinite set of propositions available to $S$ that can be arranged in a non-repeating series such that the first member, $\mathrm{R}_{1}$ is a reason for $\mathrm{P}$, and the second member, $\mathrm{R}_{2}$ is a reason for $\mathrm{R}_{1}$, and the third member, $\mathrm{R}_{3}$ is a reason for $\mathrm{R}_{2}$, and so on.

My claim is that (L) and (I) make an unhappy dyad: if (L) is true, then there is no good rationale for holding (I) (i.e. propositional infinitism). In other words, if what localized propositional infinitism claims about the origin and degree of propositional justification is true, then there is no good rationale for holding that propositional justification requires an infinitely long sequence of reasons. ${ }^{31}$

I suspect that the claim that holding (L) undermines the rationale one might have for holding (I) will strike many as obvious. If not, the following considerations might help to appreciate its force. What initiates the traditional regress of propositional justification is, plausibly, (IJC) (and, in the case of doxastic justification, (IJC*)) - the thesis that inferential propositional justification is only conditional justification. The reason why we are dissatisfied with an answer to the question "Why is the proposition that $\mathrm{P}$ justified for S?" that invokes an unsupported proposition, say, the proposition that $\mathrm{R}_{1}$, is that the support the proposition that $\mathrm{R}_{1}$ provides for the proposition that $\mathrm{P}$ is merely conditional, and such a dissatisfaction starts a regress that has long troubled philosophers of knowledge. To put it crudely, epistemic infinitism (as a non-skeptical view) is the thesis that the regress ensuing from such a questioning is real

\footnotetext{
31 The heart of the objection here is nicely captured by Ginet's following remarks: "Klein seems to...[hold] that the longer the chain of inferential justification for a given belief the greater the justification created, and that, if the chain is long enough (but still finite), the justification can "increase to the degree required for knowledge." This seems to give us the result that knowledge does not require infinitely long chain of inferential justification after all: infinitism gives way to inferentialism [the definitive claim of which is stated by (L)]" $(2005 \mathrm{~b}, \mathrm{p}$. 155). As Ginet puts it elsewhere in the same article, "inferentialism drives out infinitism" (2005b, p. 154).
} 
and skeptical worries about its infinity can be alleviated. Now, if, as (L) entails, unsupported propositions were to actually (unconditionally) justify (even to some degree) the target proposition (and hence if (IJC) were false), then there would be no regress of justification to start with (at least not of the sort that is as deeply problematic as the traditional one) and $a$ fortiori no regress that the infinitist would be in a position to fully embrace. This means that what initiates the traditional regress of propositional justification is the same thing as what makes propositional infinitism come out as an alternative account of justification, and it is (IJC). Since (L) is a way of rejecting (IJC), endorsing (L) undermines the very ground one could have for endorsing (propositional) infinitism expressed by (I). ${ }^{32}$

To sum up the discussion above, then, I would like to make the following points. Klein provides two main (and substantially different) responses to the argument from conditionality. According to one of these responses, warrant-emergent propositional infinitism is true and, if this is so, the force of the argument from conditionality is defused by undermining one of its central premises, namely, (IJC). However, I have argued that given (PAR), warrant-emergent propositional infinitism entails warrant-emergent doxastic infinitism, which in turn straightforwardly entails skepticism about doxastic justification. The other response arises from

\footnotetext{
${ }^{32}$ One might suspect that the very same reasoning here also applies to Klein's warrant-emergent propositional infinitism specified above: if, one might say, warrant-emergent propositional infinitism rejects (IJC), then if (IJC) is responsible for the initiation of the regress of justification, then rejecting (IJC) results in losing whatever rationale there might be for holding warrant-emergent propositional infinitism. However, some complications arise here. It is important here to note the difference in reasons why warrant-emergent propositional infinitism and localized propositional infinitism reject (IJC). (IJC) is the thesis that inferential propositional justification is only conditional justification in the sense that a proposition's being inferentially justified is dependent on (or arises in virtue of) another proposition's being justified (see fn. 20 above). According to warrant-emergent propositional infinitism, (IJC) thus understood is to be rejected (partly) because propositional justification, be it actual or conditional, does not emerge at all among a set of finite number of propositions among which there are inferential relations. However, rejecting (IJC) in this way is consistent with there being a regress of justification because there is a distinction between implication and dependence and also because a regress of justification might ensue not only from the latter but also from the former. However, according to localized propositional infinitism, (IJC) is to be rejected because actual propositional justification emerges among a set of finite number of propositions inferentially structured in an appropriate way. Rejecting (IJC) in this way entails not only the falsity of the dependence claim (IJC) but also the falsity of an analogous implication claim. If this is so, rejecting (IJC) in this way results in the loss of both of the grounds of a potential regress.
} 
Klein's explicit rejection of warrant-emergent doxastic infinitism and his explicit endorsement of a sort of contextualism about doxastic justification, according to which doxastic justification emerges as soon as the subject locates even a single reason for a belief and it increases as she "calls forth" more and more reasons. If Klein is right about the emergence of doxastic justification, however, then, assuming (PAR), warrant-emergent propositional infinitism needs to abandoned and what I have called localized propositional infinitism needs to be endorsed, according to which propositional justification for a proposition emerges as soon as there is a reason available to the subject for that proposition and its degree depends on the 'length' of the evidential chain available to the subject supporting that proposition. Localized propositional infinitism directly rejects (IJC) and thus is not threatened by the argument from conditionality. However, localized propositional infinitism is a combination of two different theses, one of which renders the other (at least) pointless: if propositional justification emerges and its degree increases "locally", then there is no good reason to insist that propositional justification requires an infinite chain of reasons. The upshot is a dilemma for Klein's defense of infinitism: either endorse doxastic infinitism (and skepticism about doxastic justification) or abandon propositional infinitism. Absent any further responses to the argument from conditionality that can be found in Klein's works, I conclude that his defense of epistemic infinitism, as it actually stands, is unsuccessful.

\section{References}

Aikin, S. (2005). Who is afraid of epistemology's regress problem? Philosophical Studies, 126 (2), 191217.

Aikin, S. (2008). Meta-epistemology and the varieties of epistemic infinitism. Synthese, 163, 175-185.

Aikin, S. (2011). Epistemology and the regress problem. New York: Routledge.

Alston, W. (1985). Concepts of epistemic justification. The Monist, 68 (1), 57-89.

Annis, D. (1978). A contextualist theory of epistemic justification. American Philosophical Quarterly, $15,213-219$. 
Aristotle. (1941). The basic works of Aristotle. In R. McKeon (Ed.), New York: Random House.

Bergmann, M. (2014). Klein and the infinite regress. In P. Klein \& J. Turri (Eds.), Ad Infinitum, Oxford: Oxford University Press.

Clark, R. (1988). Vicious infinite regress arguments. Philosophical Perspectives, 2, 369-380.

Cling, A. (2004). The trouble with infinitism. Synthese, 138, 101-123.

Connee, E. and R. Feldman. (2008). Evidence. In Q. Smith (Ed.), Epistemology: New Essays, Oxford: Oxford University Press.

Dancy, J. (1985). An introduction to contemporary epistemology. Oxford: Basil Blackwell Ltd.

DeRose, K. (1992). Contextualism and knowledge attributions. Philosophy and Phenomenological Research, 52, 913-929.

Empiricus, S. (1976). Outlines of Pyrrhonism. Cambridge, MA: Harvard University Press.

Evans, I. (2013). The problem of the basing relation. Synthese, 190, 2943-2957.

Fantl, J. (2003). Modest infinitism. Canadian Journal of Philosophy, 33 (4), 537-562.

Firth, R. (1978). Are epistemic concepts reducible to ethical concepts? In A. Goldman \& J. Kim (Eds.), Values and Morals, Dordrecht: Reidel Publishing Company.

Gillett, C. (2003). Infinitism redux? A response to Klein. Philosophy and Phenomenological Research, 66 (3), 709-717.

Ginet, C. (2005a). Infinitism is not the solution to the regress problem. In M. Steup \& E. Sosa (Eds.), Contemporary Debates in Epistemology, Oxford: Blackwell Publishing.

Ginet, C. (2005b). Reply to Klein. In M. Steup \& E. Sosa (Eds.), Contemporary Debates in Epistemology, Oxford: Blackwell Publishing.

Goldman, A. (1967). A causal theory of knowing. The Journal of Philosophy, 64 (12), 357-372.

Goldman, A. (1979). What is justified belief? In G. Pappas (Ed.), Justification and Knowledge, Boston: D. Reidel.

Harman, G. (1970). Knowledge, reasons, and causes. The Journal of Philosophy, 67 (21), 841-855.

Kajamies, T. (2009). A quintet, a quartet, a trio, a duo? Philosophia, 37, 525-534.

Klein, P. (1998). Foundationalism and the infinite regress of reasons. Philosophy and Phenomenological Research, 58 (4), 919-925.

Klein, P. (1999). Human knowledge and the infinite regress of reasons. Philosophical Perspectives, 13, 297-325.

Klein, P. (2000). Why not infinitism? The Proceedings of the Twentieth World Congress of Philosophy, 5, 199-208.

Klein, P. (2003). When infinite regresses are not vicious. Philosophy and Phenomenological Research, 66 (3), 718-729. 
Klein, P. (2005a). Infinitism is the solution to the regress problem. In M. Steup \& E. Sosa (Eds.), Contemporary Debates in Epistemology, Oxford: Blackwell Publishing.

Klein, P. (2005b). Reply to Ginet. In M. Steup \& E. Sosa (Eds.), Contemporary Debates in Epistemology, Oxford: Blackwell Publishing.

Klein, P. (2007a). Human knowledge and the infinite progress of reasoning. Philosophical Studies, 134, $1-17$.

Klein, P. (2007b). How to be an infinitist about doxastic justification. Philosophical Studies, 134, 2529.

Klein, P. (2011). Infinitism. In S. Bernecker \& D. Pritchard (Eds.), Routledge Companion to Epistemology, New York: Routledge.

Klein, P. (2014). No final end in sight. In R. Neta (Ed.), Current Controversies in Epistemology, New York: Routledge.

Klein, P and J. Turri (Eds.). (2014). Ad infinitum: New Essays on Epistemological Infinitism. Oxford: Oxford University Press.

Korcz, K. A. (2015). The epistemic basing relation. In E. Zalta (Ed.), The Stanford Encyclopedia of Philosophy, URL $=<$ https://plato.stanford.edu/archives/fall2015/entries/basing-epistemic/>.

Kvanvig, J. and C. Menzel. (1990). The basic notion of justification. Philosophical Studies, 59, 235261.

Leite, A. (2004). On justifying and being justified. Philosophical Issues, 14, 219-253.

Moser, P. (1984). A defense of epistemic intuitionism. Metaphilosophy, 15 (3), 196-209.

Moser, P. (1985). Whither infinite regresses of justification? The Southern Journal of Philosophy, 23 (1), 65-74.

Peijnenburg, J. and D. Atkinson. (2013). The emergence of justification. The Philosophical Quarterly, 63 (252), 546-564.

Turri, J. (2009a). On the regress argument for infinitism. Synthese, 166, 157-163.

Turri, J. (2009b). An infinitist account of doxastic justification. Dialectica, 63 (2), 209-218.

Turri, J. (2010a). Foundationalism for modest infinitists. Canadian Journal of Philosophy, 40 (2), 275284.

Turri, J. (2010b). On the relationship between propositional and doxastic justification. Philosophy and Phenomenological Research, 80 (2), 312-326.

Turri, J. (2014). Creative reasoning. In P. Klein \& J. Turri (Eds.), Ad Infinitum, Oxford: Oxford University Press.

Wright, S. (2013). Does Klein's infinitism offer a response to Agrippa's trilemma? Synthese, 190, 11131130 . 